\title{
ANÁLISE ENERGÉTICA EM SISTEMA DE PRODUÇÃO DE SUÍNOS COM APROVEITAMENTO DOS DEJETOS COMO BIOFERTILIZANTE EM PASTAGEM ${ }^{1}$
}

\author{
CÁSSIO V. SOUZA ${ }^{2}$, ALESSANDRO T. CAMPOS ${ }^{3}$, OSMAR C. BUENO ${ }^{4}$, \\ ENILSON B. SILVA
}

\begin{abstract}
RESUMO: O objetivo deste trabalho foi estimar a quantidade de energia para a produção de suínos, em ciclo completo, e o balanço energético do sistema com reaproveitamento dos resíduos gerados como biofertilizante, em área de pastagem, utilizando dados médios de cinco ciclos, em granja comercial no município de Diamantina - MG. Quantificou-se o coeficiente energético de cada componente envolvido no processo produtivo de suínos terminados, tratamento dos resíduos e produção de pastagem de Brachiaria decumbens, nas formas de ração, trabalho humano, energia elétrica, máquinas e equipamentos, combustíveis e lubrificantes, instalações, produção de suínos vivos e produção de Brachiaria decumbens. A quantidade média de energia para produzir $1 \mathrm{~kg}$ de suíno vivo foi de 53,35 MJ. De toda energia empregada no sistema, 76,03\% (1.067.106,07 MJ) referem-se às entradas e 23,97\% (331.400 MJ) às saídas, resultando em coeficiente de eficiência energética de 0,31. A energia transformada em suínos para abate correspondeu a 55,58\% (184.200 MJ) das saídas, ao passo que a pastagem de Brachiaria decumbens assumiu o valor de $44,42 \%(147.200 \mathrm{MJ})$.
\end{abstract}

PALAVRAS-CHAVE: suinocultura, instalações, tratamento de dejetos, lagoas de estabilização, Brachiaria decumbens, energia.

\section{ENERGY ANALYSIS IN A SWINE PRODUCTION SYSTEM WITH USE OF MANURE AS BIOFERTILIZER IN PASTURE}

\begin{abstract}
This work objective was to esteem the amount of energy employed in a complete cycle swine production and the energy balance of the system with utilization of the generated manure as biofertilizer in pasture area, by using five cycles' average data, in a commercial farm in Diamantina municipal district - MG Brazil. The energy coefficient of each involved component was quantified in the productive process of finished swine, residues treatment and Brachiaria decumbens pasture production, in the form of ration, human labor, electric power, machines and equipments, fuel and lubricants, buildings, finished swine production and Brachiaria decumbens production. The average quantity of energy to produce $1 \mathrm{~kg}$ of alive swine was of $53.35 \mathrm{MJ}$. Of total employed energy in the system $76.03 \%(1,067,106.07 \mathrm{MJ})$ refers to the inputs and $23.97 \%$ $(331,400 \mathrm{MJ})$ refers to the outputs, resulting in an energy efficiency coefficient of 0.31 . The energy converted in swine for abate corresponded to $55.58 \%(184,200 \mathrm{MJ})$ of the outputs, while the pasture of Brachiaria decumbens reached a value of $44.42 \%$ (147,200 MJ).
\end{abstract}

KEYWORDS: swine, buildings, manure treatment, stabilization ponds, Brachiaria decumbens, energy.

\footnotetext{
${ }^{1}$ Projeto desenvolvido com o apoio financeiro do CNPq.

${ }^{2}$ M.Sc. em Produção Vegetal, UFVJM, Rua da Glória, 187, Diamantina - MG, Bolsista da CAPES, agro.cassio@ hotmail.com

${ }^{3}$ Prof. Adjunto, Departamento de Engenharia, UFLA, Lavras - MG, campos@ deg.ufla.br

${ }^{4}$ Prof. Adjunto, Faculdade de Ciências Agronômicas, UNESP, Câmpus de Botucatu - SP.

${ }^{5}$ Prof. Adjunto, Departamento de Agronomia, UFVJM.

Recebido pelo Conselho Editorial em: 20-11-2008

Aprovado pelo Conselho Editorial em: 28-8-2009
} 


\section{INTRODUÇÃO}

A crise energética do mundo atual reflete em vários aspectos da vida humana. A utilização irracional das fontes de energia não renováveis está contribuindo diretamente para a degradação do meio ambiente e consequente diminuição dos recursos naturais. $\mathrm{O}$ mesmo ocorre na produção agropecuária, devido à grande demanda por alimentos, implica-se elevada utilização de máquinas e recursos não renováveis, como combustíveis fósseis e fertilizantes, comprometendo a sustentabilidade dos agroecossistemas.

O estudo da energia empregada em sistemas agrícolas, seus fluxos, distribuição e conversão constituem importante instrumental para a avaliação da sustentabilidade desses sistemas, principalmente considerando as crises no setor energético. Esse procedimento possibilita a determinação dos processos, materiais e equipamentos de maior consumo energético, indicando opções de economia (TEIXEIRA et al., 2005; CAMPOS et al., 2003).

De acordo com PRACUCHO et al. (2007), considerando-se a importância crescente que sistemas de produção agrícolas mais sustentáveis vêm adquirindo, torna-se importante analisar as eficiências energética e econômica como mais um indicativo da sustentabilidade ambiental, particularmente pelo uso de fluxos de energia não renovável, e a sustentabilidade econômica, condição para a permanência dos produtores agrícolas na atividade.

O balanço energético visa a estabelecer os fluxos de energia, identificando sua demanda total, a eficiência energética refletida pelo ganho líquido de energia e pela relação saída/entrada (energia produzida/energia empregada) e a energia necessária para produzir ou processar um quilograma de determinado produto (SIQUEIRA et al., 1999).

Os sistemas intensivos de produção agrícola têm causado sérios danos ambientais caracterizados, por um lado, pelo rápido esgotamento de recursos naturais e, por outro, pela poluição e/ou contaminação devido à excessiva liberação de componentes residuais no meio ambiente (ROMERO et al., 2008; KOSIOSKI \& CIOCCA, 2000). Como todo processo de produção gera resíduos e todo resíduo armazena alguma energia, os sistemas de produção podem reverter esse resíduo em energia, baratear seu custo de produção e funcionar de forma energeticamente equilibrada (SANTOS \& LUCAS JÚNIOR, 2004).

Devido à expansão da atividade suinícola no País e ao aumento tecnológico da atividade, grande volume de dejetos é gerado, o qual, na maioria das vezes, é lançado em rios e mananciais. Devido à adoção de sistemas confinados de produção de suínos, grandes quantidades de dejetos são produzidas (PEREIRA et al., 2008; BELLI FILHO et al., 2001; GOMES FILHO et al., 2001; OLIVEIRA, 1993).

A análise dos agroecossistemas sob a óptica de seus fluxos energéticos pode ser um instrumento para a avaliação de balanço energético em sistemas de produção de suínos (ANGONESE et al., 2006), atuando como ferramenta auxiliar na avaliação da sustentabilidade.

Dessa forma, o presente trabalho teve como objetivo estimar a quantidade de energia para a produção de suínos em ciclo completo e o balanço energético do sistema com reaproveitamento dos resíduos gerados como biofertilizante em área de pastagem.

\section{MATERIAL E MÉTODOS}

O estudo foi realizado em sistema de produção de suínos em ciclo completo com aproveitamento dos resíduos como biofertilizante em áreas de pastagens de Brachiaria decumbens, na Fazenda Campo Alegre, localizada no município de Diamantina, na região do Vale do Jequitinhonha - MG, situada à latitude de $18^{\circ} 15^{\prime}$ ' sul e longitude de $43^{\circ} 36^{\prime}$ oeste, com altitude de $1.250 \mathrm{~m}$. O clima é classificado como $\mathrm{Cwb}$ (Köeppen), temperado úmido, com inverno seco e chuvas no verão, com precipitação média anual de $1.400 \mathrm{~mm}$. 


\section{Sistema de produção de suínos}

A unidade de produção de suínos é definida por galpões construídos em blocos de concreto pré-moldados, divididos de acordo com as fases de produção, gestação e pré-gestação, maternidade, creche, crescimento e terminação, perfazendo o total de $1.200 \mathrm{~m}^{2}$ de área interna das instalações. $\mathrm{O}$ telhado é construído de telhas de cimento amianto, suportada por pilares de concreto, com estrutura de cobertura em tesouras de madeira e beiral de $0,7 \mathrm{~m}$. Os dejetos são manejados na forma líquida e conduzidos por canaletas laterais tampadas com chapas de aço galvanizado, a fim de não receber águas pluviais que promoveriam o aumento do volume dos dejetos.

A granja possui plantel de 500 animais, dentre os quais estão 60 matrizes e quatro reprodutores.

\section{Sistema de tratamento dos dejetos}

O sistema utilizado para o tratamento dos dejetos é composto por três lagoas de estabilização em série, sendo a primeira anaeróbia e as duas subsequentes facultativas. Foram dimensionadas em função da vazão diária de dejetos líquidos $\left(5,7 \mathrm{~m}^{3}\right)$ e do tempo de retenção hidráulica (TRH) (SPEARLING, 1996). A lagoa anaeróbia possui TRH de 45 dias, dimensões externas de $23,50 \times 8 \mathrm{~m}$, dimensões internas de $19,5 \times 4 \mathrm{~m}$, profundidade de $2 \mathrm{~m}$ e volume de $260 \mathrm{~m}^{3}$. A primeira lagoa facultativa opera com TRH de 35 dias, dimensões externas de 18,5 x 8,5 m, dimensões internas de 15,5 x 5,5, profundidade de $1,5 \mathrm{~m}$ e volume de $175 \mathrm{~m}^{3}$. A segunda lagoa facultativa opera com TRH de 25 dias, dimensões externas de 13 x 8,5 m, dimensões internas de $10 \times 5,5 \mathrm{~m}$, profundidade de $1,5 \mathrm{~m}$ e volume de $120 \mathrm{~m}^{3}$. As lagoas foram impermeabilizadas com plástico de $200 \mu \mathrm{m}$ e recebem os dejetos por gravidade por meio de tubulações de PVC.

\section{Sistema de produção de pastagem}

A propriedade possui área de 8 ha destinada à produção de Brachiaria decumbens, utilizando como prática de manutenção somente a aplicação de todo o biofertilizante advindo do sistema de tratamento dos efluentes da suinocultura, na dosagem de $260 \mathrm{~m}^{3} \mathrm{ha}^{-1}$ ano $^{-1}$, não havendo adubação química nem correção de acidez. No manejo convencional da propriedade onde se localiza a região estudada, o biofertilizante é aplicado na pastagem em área total (8 ha), o que não permitiu incluir um tratamento-testemunha, com aplicação de água e/ou fertilizantes químicos. Dessa forma, não houve comparação dos ganhos de matéria seca relativos à aplicação do biofertilizante com outros sistemas de manejo de adubação da pastagem.

\section{Matriz energética}

A delimitação do sistema estudado deu-se pelas atividades relativas ao trato e ao manejo das matrizes e dos reprodutores e produção de suínos terminados para o abate, tratamento dos resíduos gerados pela atividade e aplicação do biofertilizante na área de pastagem.

O período de acompanhamento do sistema foi de fevereiro de 2006 a março de 2008, avaliando dados médios de cinco lotes ou ciclos, desde o nascimento dos leitões até a saída para o abate, resultando em período de 150 dias por ciclo.

Como energia direta, ou seja, a energia aplicada diretamente no sistema produtivo, considerou-se aquela relativa à ração, à energia elétrica, aos combustíveis e aos insumos diretamente consumidos no sistema (BONNY, 1993). Como energia indireta, considerou-se aquela empregada na fabricação de equipamentos, nas construções e nas instalações, na irrigação e outras inputs necessários à produção (CLEVELAND, 1995). Para tanto, utilizou-se da metodologia desenvolvida por DOERING III et al. (1977), a mesma adotada por vários autores (BEBER, 1989; COMITRE, 1995; CARVALHO \& LUCAS JÚNIOR, 2001; ZANINI et al., 2003; CAMPOS et al., 2005; ANGONESE et al., 2006) e baseia-se na depreciação energética, levando em consideração o tempo de utilização e a vida útil dos equipamentos. 


\section{Componentes e coeficientes energéticos e conversão energética}

Ração: a quantidade de energia referente à ração para suínos foi estimada por meio do coeficiente energético de $17 \mathrm{MJ} \mathrm{kg}^{-1}$, preconizado por OETTING (2002), relacionado com a quantidade média de ração consumida por matrizes, varões e pelos leitões dos lotes acompanhados. Combustíveis e lubrificantes: os coeficientes utilizados para óleo diesel, óleo lubrificante e graxa foram os estabelecidos por SERRA et al. (1979), e são, respectivamente, 43,93 MJ L-1, 43,908 $\mathrm{MJ} \mathrm{L}^{-1}$ e 49,224 $\mathrm{MJ} \mathrm{kg}^{-1}$.

Energia Elétrica: a composição energética relativa ao consumo de energia elétrica foi realizada pelo consumo médio diário da granja, em $\mathrm{kWh}$, no período avaliado, e relacionou-se com o coeficiente energético de 13,11 $\mathrm{MJ} \mathrm{KWh}^{-1}$ (BRASIL, 2007).

Trabalho humano: considerou-se a energia advinda do trabalho realizado pelos funcionários efetivamente utilizada na produção de suínos e pastagem. Foi contabilizada a carga horária média por ciclo, multiplicando-se pelo coeficiente energético de 4,39 MJ hora ${ }^{-1}$ homem $^{-1}$ (PIMENTEL, 1980).

Instalações: a composição energética da construção dos galpões foi estimada de acordo com a área ocupada pelas instalações e o coeficiente energético estabelecido para instalações suinícolas de 956,03 $\mathrm{MJ} \mathrm{m}^{-2}$ (ANGONESE, 2006).

Máquinas e equipamentos: a metodologia utilizada foi baseada na depreciação energética que, a partir da massa das máquinas e equipamentos, consiste em depreciá-los ao longo de sua vida útil (DOERING III et al., 1977). O coeficiente adotado para equipamentos autopropelidos, como o trator, foi de 69,83 $\mathrm{MJ} \mathrm{kg}^{-1}$; para o distribuidor de biofertilizante, foi adotado o coeficiente de $57,20 \mathrm{MJ} \mathrm{kg}^{-1}$ (MACÊDONIO \& PICCHIONI, 1985), e para outros equipamentos relacionados ao sistema produtivo, o coeficiente de 83,71 $\mathrm{MJ} \mathrm{kg}^{-1}$ (PIMENTEL, 1980).

Lagoas de estabilização: a composição energética das lagoas de estabilização (Tabela 1) foi estimada a partir dos coeficientes energéticos dos seus componentes construtivos estabelecidos por diversos autores. Adotou-se a metodologia proposta por DOERING III et al. (1977), considerando vida útil de 20 anos para as lagoas de estabilização (SPEARLING, 1996). Contabilizou-se, também, a energia direta empregada na construção das mesmas.

TABELA 1. Componentes de entradas energéticas referentes às lagoas de estabilização e seus respectivos coeficientes energéticos. Energy inputs compounds related to stabilization ponds and its respective energy coefficients.

\begin{tabular}{|c|c|c|c|}
\hline Componente de Entrada & Coeficiente Energético & Unidades & Vida Útil \\
\hline \multicolumn{4}{|l|}{ Energia Direta } \\
\hline Trabalho humano & 4,39 & MJ homem ${ }^{-1} h^{-1}$ & \\
\hline Óleo diesel $^{2}$ & 43,93 & $\mathrm{MJ} \mathrm{L}^{-1}$ & \\
\hline Óleo lubrificante ${ }^{2}$ & 43,908 & $\mathrm{MJ} \mathrm{L}^{-1}$ & \\
\hline $\operatorname{Graxa}^{2}$ & 49,224 & $\mathrm{MJ} \mathrm{kg}^{-1}$ & \\
\hline \multicolumn{4}{|l|}{ Energia Indireta } \\
\hline Retroescavadeira CASE $580 \mathrm{M}^{3}$ & 57,2 & $\mathrm{MJ} \mathrm{kg}^{-1}$ & 10.000 horas \\
\hline Caminhão $1113^{3}$ & 57,2 & $\mathrm{MJ} \mathrm{kg}^{-1}$ & 10.000 horas \\
\hline Lona Plástica $200 \mathrm{~m} \mu^{4}$ & 130 & $\mathrm{MJ} \mathrm{kg}^{-1}$ & \\
\hline Tubulações de PVC $^{1}$ & 120 & $\mathrm{MJ} \mathrm{kg}^{-1}$ & 40 anos \\
\hline
\end{tabular}

${ }^{T}$ PIMENTEL (1980); ${ }^{2}$ SERRA et al. (1979); ${ }^{3}$ MACEDÔNIO \& PICCHIONI (1985); ${ }^{4}$ PELLIZZI (1992).

No estudo realizado, não foram incluídos insumos energéticos relativos a matrizes e varões pelo fato de o sistema já se encontrar estabilizado. Também não foi computada a energia relativa à implantação da pastagem de Brachiaria decumbens, por ser uma pastagem já implantada por longo período de tempo, assumindo representação insignificante no aporte de energia. 
Foi considerada como energia útil aquela disponível na forma de suínos para o abate, assumindo 9,21 $\mathrm{MJ} \mathrm{kg}^{-1}$ de peso vivo (COMITRE, 1995; QUESADA et al., 1987), e a energia passível de recuperação na forma de Brachiaria decumbens fertilizada com o efluente das lagoas de estabilização, assumindo valor de coeficiente energético de $8 \mathrm{MJ} \mathrm{kg}^{-1}$ de matéria seca (PELLIZZI, 1992).

A produção média por ciclo foi de 200 leitões, com o peso médio de $100 \mathrm{~kg}$, totalizando $20.000 \mathrm{~kg}$ de suínos para o abate.

A produção da pastagem foi mensurada utilizando metodologia adotada por OLIVEIRA (2006), avaliando a quantidade total de matéria seca produzida no período avaliado (fevereiro de 2006 a março de 2008), dividida pelos cinco ciclos observados durante esse período. A produção média de pastagem de Brachiaria decumbens por período de 150 dias foi de 2,3 $\mathrm{t} \mathrm{ha}^{-1}$ de matéria seca, chegando ao valor médio de 18,4 t de matéria seca da pastagem nos 8 ha.

\section{Coeficiente de eficiência energética}

O coeficiente de eficiência energética $(\eta)$ foi estimado por meio da razão entre a energia convertida e a energia consumida pelo agroecossistema (QUESADA et al., 1991), segundo a eq.(1):

$$
\eta=\frac{\sum \text { E Convertida }}{\sum \mathrm{E} \text { Entrada }}
$$

em que,

$\sum \mathrm{E}$ Convertida $=\sum$ das energias convertidas no processo de produção, e

$\sum E$ Entrada $=\sum$ das energias direta e indireta consumida no processo de produção.

\section{RESULTADOS E DISCUSSÃO}

$\mathrm{Na}$ Tabela 2, apresenta-se a média dos componentes relativos à entrada de energia e à quantidade utilizada em cada input no período avaliado.

TABELA 2. Quantificação média dos componentes energéticos envolvidos no sistema de produção de um lote de suínos (150 dias) e aproveitamento do biofertilizante em área de pastagem. Average quantification of the energetic compounds in the production system in a swine batch (150 days) and use of biofertilizer in pasture area.

\begin{tabular}{|c|c|}
\hline Componente de Entrada & Quantidade \\
\hline \multicolumn{2}{|l|}{ Energia Direta } \\
\hline Ração & $49.500 \mathrm{~kg}$ \\
\hline Óleo diesel & $2.223 \mathrm{~L}$ \\
\hline Óleo lubrificante & $54,72 \mathrm{~L}$ \\
\hline Graxa & $13,68 \mathrm{~kg}$ \\
\hline Energia elétrica & $7.500 \mathrm{kWh}$ \\
\hline Trabalho humano & 1.800 horas \\
\hline \multicolumn{2}{|l|}{ Energia Indireta } \\
\hline Instalações & $1.200 \mathrm{~m}^{2}$ \\
\hline Trator $50 \mathrm{cv}$ & 1 unidade \\
\hline Distribuidor de biofertilizante & 1 unidade \\
\hline Outros equipamentos ${ }^{1}$ & - \\
\hline Lagoas de estabilização & 3 unidades \\
\hline
\end{tabular}

${ }^{1}$ Referem-se a pequenos utensílios utilizados no cotidiano da granja.

Encontram-se, na Tabela 3, as máquinas, implementos e equipamentos utilizados no sistema de produção estudado, o consumo de combustível e tempo de utilização. O peso, consumos de óleo 
diesel, óleo lubrificante e graxa dos itens foram estimados a partir do manual das máquinas e dos equipamentos.

$\mathrm{Na}$ Tabela 4, apresentam-se as máquinas utilizadas no processo de construção das lagoas de estabilização, com seus respectivos pesos, vida útil, horas de utilização e consumo de combustíveis e lubrificantes. O peso, o consumo de óleo diesel, o óleo lubrificante e a graxa foram estimados a partir do manual das máquinas.

TABELA 3. Máquinas, implementos e equipamentos utilizados no sistema de produção de suínos e pastagem: consumo médio de combustível e tempo de utilização por ciclo de 150 dias. Machinery, implements and equipment used in the swine production system and pasture: fuel consumption average and utilization time per 150 days cycle.

\begin{tabular}{|c|c|c|c|c|c|c|}
\hline \multirow[b]{2}{*}{ Item } & \multirow[b]{2}{*}{$\begin{array}{c}\text { Peso } \\
(\mathrm{kg})\end{array}$} & \multicolumn{3}{|c|}{ Consumo } & \multirow{2}{*}{$\begin{array}{c}\text { Tempo de } \\
\text { Utilização (horas) }\end{array}$} & \multirow[b]{2}{*}{$\begin{array}{l}\text { Vida Útil } \\
\text { (horas) }\end{array}$} \\
\hline & & $\begin{array}{l}\text { Diesel } \\
(\mathrm{L})\end{array}$ & $\begin{array}{l}\text { Lubrificante } \\
\text { (L) }\end{array}$ & $\begin{array}{c}\text { Graxa } \\
(\mathrm{kg})\end{array}$ & & \\
\hline$\overline{\text { Trator } 36,75 \mathrm{~kW}(50 \mathrm{cv})}$ & 2.200 & 2.223 & 54,72 & 10,68 & 342 & 10.000 \\
\hline Distribuidor de biofertilizante & 1.300 & - & - & 3,0 & 342 & 10.000 \\
\hline Outros equipamentos $^{1}$ & 46 & - & - & - & 1.800 & 262.800 \\
\hline
\end{tabular}

${ }^{1}$ Refere-se a pequenos utensílios utilizados no cotidiano da granja.

TABELA 4. Máquinas utilizadas na construção das lagoas de estabilização: consumo de combustível e tempo de utilização. Machinery used in the stabilization ponds construction: fuel consumption and time of use.

\begin{tabular}{|c|c|c|c|c|c|c|}
\hline \multirow[b]{2}{*}{ Item } & \multirow[b]{2}{*}{$\begin{array}{l}\text { Peso } \\
(\mathrm{kg})\end{array}$} & \multicolumn{3}{|c|}{ Consumo } & \multirow[b]{2}{*}{$\begin{array}{c}\text { Tempo de } \\
\text { Utilização (horas) }\end{array}$} & \multirow[b]{2}{*}{$\begin{array}{l}\text { Vida Útil } \\
\text { (horas) }\end{array}$} \\
\hline & & $\begin{array}{l}\text { Diesel } \\
\text { (L) }\end{array}$ & $\begin{array}{l}\text { Lubrificante } \\
\text { (L) }\end{array}$ & $\begin{array}{c}\text { Graxa } \\
(\mathrm{kg})\end{array}$ & & \\
\hline Retroescavadeira CASE $580 \mathrm{M}$ & 6.522 & 308 & 11,2 & 7 & 56 & 10.000 \\
\hline Caminhão 1113 & 6.620 & 492 & 8,0 & 3 & 30 & 10.000 \\
\hline
\end{tabular}

Não foram encontrados na literatura coeficientes energéticos referentes a lagoas de estabilização em série. Dessa forma, a composição energética referente a essa entrada foi determinada a partir dos coeficientes energéticos dos materiais empregados no processo construtivo e da energia direta empregada na construção das mesmas, como apresentada na Tabela 5.

TABELA 5. Quantificação dos componentes energéticos envolvidos na construção das lagoas de estabilização. Quantification of energy components involved in the stabilization ponds construction.

\begin{tabular}{lc}
\hline Componente de Entrada & Quantidade \\
\hline Energia Direta & \\
Trabalho humano & 216 horas \\
Óleo diesel & $800 \mathrm{~L}$ \\
Óleo lubrificante & $19,2 \mathrm{~L}$ \\
Graxa & $10 \mathrm{~kg}$ \\
\hline Energia Indireta & 1 unidade \\
Retroescavadeira CASE 580 M & 1 unidade \\
Caminhão 1113 & $126 \mathrm{~kg}$ \\
Lona Plástica 200 m $\mu$ & $90 \mathrm{~kg}$ \\
Tubulações de PVC
\end{tabular}


Na Tabela 6, sintetiza-se toda a energia empregada no sistema produtivo. Observou-se maior consumo na categoria direta, contribuindo com 98,25\% do total de entradas de energia, ao passo que a energia indireta assumiu pequena participação de $1,75 \%$ do total de entradas.

Analisou-se, também, o consumo de energia nas diversas categorias, destacando-se a preponderância do aporte de energia referente à ração utilizada na alimentação dos animais, que correspondeu a 80,26\% do total de energia direta empregada no sistema. Esses valores corroboram aqueles encontrados por outros autores, como SANTOS \& LUCAS JÚNIOR (2004), que, trabalhando com balanço de energia em galpão de frangos de corte, observaram que a ração compôs $86,5 \%$ do total de energia direta. ANGONESE et al. (2006), em trabalho com suínos em terminação, apontaram a ração como o componente de maior aporte de energia no processo (95,28\% do total de energia direta). CARVALHO \& LUCAS JÚNIOR (2001), em trabalho de balanço energético em granjas de postura, observaram que a ração para as aves foi responsável por $84,70 \%$ da energia consumida pelo sistema, também sendo o componente de maior aporte de energia.

TABELA 6. Consumo médio de energia direta e indireta no sistema de produção de suínos e pastagem para o período de 150 dias. Average of direct and indirect energy consumption in the swine production system and pasture for a 150 days period.

\begin{tabular}{lcc}
\hline \multicolumn{1}{c}{ Entradas de Energia } & Consumo de Energia (MJ) & Consumo de Energia (\%) \\
\hline Energia direta & $1.048 .459,42$ & 98,25 \\
Ração & $841.500,00$ & 80,26 \\
Combustíveis e lubrificantes & $100.732,42$ & 9,61 \\
Energia elétrica & $98.325,00$ & 9,38 \\
Trabalho humano & $7.902,00$ & 0,75 \\
\hline Energia indireta & $18.646,65$ & 1,75 \\
Instalações & $9.429,33$ & 50,56 \\
Máquinas e equipamentos & $7.823,50$ & 41,97 \\
Lagoas de estabilização & $1.393,92$ & 7,47 \\
\hline Total entrada & $1.067 .106,07$ & 100,00 \\
\hline
\end{tabular}

Outros itens relacionados à energia direta empregada no sistema, como combustíveis e lubrificantes e trabalho humano, apresentaram valores baixos, contribuindo pouco para a composição energética, sendo que combustíveis e lubrificantes representaram 9,61\% (100.732,42 MJ), contrastando com os valores obtidos por autores como ZANINI et al. (2003), CAMPOS et al. (2004) e CAMPOS et al. (2005) que, trabalhando com culturas forrageiras, observaram que os combustíveis e os lubrificantes apresentaram, respectivamente, 47,74; 59,61 e 75,05\% do consumo total de energia, assumindo maior contribuição no aporte de energia direta dos sistemas estudados.

O trabalho humano apresentou pequena parcela de 0,75\% (7.902,00 MJ) do total da energia direta, mostrando que a atividade tem dependência mínima de trabalho humano, comparado com as demais entradas de energia direta, o que vai de acordo com o observado por diversos autores (ROMERO et al., 2008; PRACUCHO et al., 2007; ANGONESE et al., 2006; CAMPOS et al., 2005; SANTOS \& LUCAS JÚNIOR, 2004) que, trabalhando com análise energética nos agroecossistemas atuais, observaram que o trabalho humano apresenta pequena percentagem no aporte de energia.

A energia elétrica apresentou valor de 9,38\% (98.325,00 MJ) da energia direta e valor de $491 \mathrm{kWh}$ para produzir um suíno terminado, correspondendo a $4,91 \mathrm{kWh} \mathrm{kg}^{-1}$ de suíno. TURCO et al. (2002) observaram valor médio de $0,1598 \mathrm{kWh}$ para produzir uma ave de corte. Tendo em vista que o frango pesa em média $2,584 \mathrm{~kg}$ na fase de abate, conforme informam RODRIGUES et al. (2008), perfazendo-se o valor de $0,62 \mathrm{kWh} \mathrm{kg}^{-1}$ de frango. Esses valores demonstram, nesse caso específico, maior dependência da energia elétrica pela suinocultura em 
ciclo completo, em que, na fase de maternidade, emprega-se o calor oriundo de lâmpadas elétricas em maior número e potência.

A energia indireta consumida durante o acompanhamento do sistema foi $18.646,65 \mathrm{MJ}$, sendo que o percentual empregado nas instalações foi próximo ao observado por ANGONESE et al. (2006), que apontaram o valor de 55\% para as construções, o maior entre os componentes de energia indireta. Neste estudo, o valor foi de 50,56\% (9.429,33 MJ) da energia indireta, seguido pelas máquinas e equipamentos com 41,97\% (7.823,50 MJ) e pelas lagoas de estabilização, que contribuíram com 7,47\% (1.393,92 MJ) e apresentaram coeficiente energético de 2,51 MJ m$~^{-3}$ de lagoa construída.

\section{Consolidação do balanço energético}

Na Tabela 7, apresentam-se, de forma sintética, todas as entradas e saídas de energia, na forma direta e indireta, e a eficiência energética do sistema estudado.

TABELA 7. Análise energética média dos componentes da relação Entrada/Saída para o ciclo de produção de suínos e aproveitamento do biofertilizante. Average energy analysis of the compounds of the input/output relation for the swine production cycle and the biofertilizer utilization.

\begin{tabular}{cc}
\hline Fontes de Entrada/Saída & Quantidade (MJ) \\
\hline Entrada (“Inputs") & \\
Energia direta total & $1.048 .459,42$ \\
Energia indireta total & $18.646,65$ \\
Total Entradas & $1.067 .106,07$ \\
\hline Saídas (“Outputs”) & 184.200 \\
Suínos & 147.200 \\
Brachiaria decumbens & 331.400 \\
Total Saídas & $-735.706,07$ \\
\hline Balanço Energético & 0,31 \\
\hline Eficiência energética
\end{tabular}

Considerando-se o total de energia que é convertida no sistema, a energia relativa à saída, na forma de suínos terminados, foi a mais relevante, representando 55,58\% (184.200 MJ) das saídas de energia, corroborando o valor encontrado por ANGONESE et al. (2006) que, em trabalho de balanço de energia com tratamento dos resíduos em biodigestor, observaram que suínos para abate corresponderam a 56,8\% das saídas de energia, seguido pela produção de biofertilizante (30,2\%) e pelo biogás $(13 \%)$ oriundo da biodigestão anaeróbia. Contudo, os autores não avaliaram a contribuição dos resíduos da suinocultura para a produção vegetal, como feito no presente trabalho.

A pastagem de Brachiaria decumbens assumiu o valor de 44,42\% (147.200 MJ) do total de energia de saída (Outputs). OLIVEIRA (2006) verificou maior produção da pastagem de Brachiaria decumbens fertirrigada com dejetos líquidos de suínos, comparada à irrigação somente com água. Resultados semelhantes também são observados para pastagens de Brachiaria brizanta (BARNABÉ et al., 2007), Capim-Marandu (MEDEIROS et al., 2007), Capim-Tifton 85 (DRUMOND et al., 2006) e pastagens naturais (CERETTA et al., 2003), o que demonstra que o agroecossistema estudado vai de acordo com o proposto por DRUMOND et al. (2006), que afirmam que a aplicação de águas residuárias da suinocultura como biofertilizante tem apresentado resultados, evidenciando que devem ser utilizados como insumo útil e econômico na produção agropecuária.

O coeficiente de eficiência energética obtido neste trabalho aponta melhor nível de sustentabilidade, se comparado ao coeficiente de eficiência energética de 0,06 obtido por QUESADA et al. (1987), em sistema de produção de suínos em ciclo completo, e também acima do 
coeficiente de 0,28 obtido por SANTOS \& LUCAS JÚNIOR (2004), trabalhando com frangos de corte.

Quando associado o resíduo da cadeia suinícola como insumo na cadeia produtiva de pastagem de Brachiaria decumbens, nesse caso específico, obteve-se o coeficiente de eficiência energética de 0,31, bem próximo ao observado por ANGONESE et al. (2006) que, trabalhando em sistema integrando suinocultura com tratamento dos resíduos em biodigestor, com produção de biofertilizante, obtiveram o valor de 0,38 .

BEBER (1989) e QUESADA et al. (1987) afirmam que valores de coeficiente de eficiência energética $(\eta)$ menores que 1 demonstram que o sistema importa grande quantidade de energia consumida no processo produtivo, o que é uma característica de sistemas altamente tecnificados, como no caso da suinocultura moderna.

\section{AGRADECIMENTOS}

Ao $\mathrm{CNPq}$, pelo apoio financeiro no desenvolvimento do projeto, e à CAPES, pela concessão de bolsa de estudos de Mestrado ao primeiro autor.

\section{CONCLUSÕES}

A quantidade média de energia requerida para produzir $1 \mathrm{~kg}$ de suíno vivo, no sistema estudado, foi de 53,35 MJ.

O componente energético mais expressivo no sistema foi o relativo à ração, correspondendo a $80,26 \%$ do total de energia direta.

Nas saídas de energia do sistema, o componente energético relativo a suínos assumiu o valor de 184.200 MJ, correspondendo a 55,58\%.

De toda a energia envolvida no agroecossistema estudado, 76,03\% referem-se à energia que entra no sistema e $23,76 \%$ corresponde à energia de saída, resultando em coeficiente de eficiência energética de 0,31 (31\%).

A produção de pastagem de Brachiaria decumbens assumiu um valor energético considerável (44,42\% da energia que sai do sistema), apontando que a utilização dos resíduos da cadeia suinícola promoveu renovação de energia, reduzindo os impactos ambientais e minimizando a importação de energia.

\section{REFERÊNCIAS}

ANGONESE, A.R.; CAMPOS, A.T.; ZACARKIM, C.E.; MATSUO, M.S.; CUNHA, F. Eficiência energética de sistema de produção de suínos com tratamento de resíduos em biodigestor. Revista Brasileira de Engenharia Agrícola e Ambiental, Campina Grande, v.10, n.3, p.745-750, 2006.

BARNABÉ, M.C.; ROSA, B.; LOPES, E.L.; ROCHA, G.P.; FREITAS, K.R.; PINHEIRO, E.P. Produção e composição químico-bromatológica da Brachiaria brizantha cv. Marandu adubada com dejetos líquidos de suínos. Ciência Animal Brasileira, Goiânia, v.8, n.3, p.435-446, 2007.

BEBER, J.A.C. Eficiência energética e processos de produção em pequenas propriedades rurais, Agudo - RS. 1989. 295 f. Dissertação (Mestrado em Extensão Rural) - Universidade Federal de Santa Maria, Santa Maria, 1989.

BELLI FILHO, P.; CASTILHOS JÚNIOR, A.B.; COSTA, R.H.R.; SOARES, S.R.; PERDOMO, C.C. Tecnologias para o tratamento de dejetos de suínos. Revista Brasileira de Engenharia Agrícola e Ambiental, Campina Grande, v.5, n.1, p.166-170, 2001.

BONNY, S. Is agriculture using more and more energy? A French case study. Agricultural Systems, Kidlington, v.43, n.1, p.51-66, 1993. 
BRASIL. Ministério de Minas e Energia. Balanço energético nacional. Brasília, 2007. 192 p.

CAMPOS, A.T.; SAGLIETTI, J.R.C.; BUENO, O.C.; CAMPOS, A.T.; KLOSOWSKI, E.S.; GASPARINO, E. Balanço energético na produção de feno de alfafa em sistema intensivo de produção de leite. Ciência Rural, Santa Maria, v.34, n.1, p.245-251, 2004.

CAMPOS, A.T.; SAGLIETTI, J.R.C.; CAMPOS, A.T.; BUENO, O.C.; RESENDE, H.; GASPARINO, E.; KLOSOWSKI, E.S. Custo energético de construção de uma instalação para armazenagem de feno. Ciência Rural, Santa Maria, v.33, n.4, p.667-672, 2003.

CAMPOS, A.T.; SAGLIETTI, J.R.C.; CAMPOS, A.T.; BUENO, O.C. Análise energética na produção de feno de Cynodon dactylon (L.) Pers. Engenharia Agrícola, Jaboticabal, v.25, n.2, p.349-358, 2005.

CARVALHO, S.M.R.; LUCAS JÚNIOR, F. Balanço energético e potencial de produção de biogás em granja de postura comercial na região de Marília - SP. Energia na Agricultura, Botucatu, v.16, n.1, p.40-61, 2001.

CERETTA, C.A.; DURIGON, R.; BASSO, C.J.; BARCELLOS, L.A.R.; VIEIRA, F.C.B.

Características químicas de solo sob aplicação de esterco líquido de suínos em pastagem natural. Pesquisa Agropecuária Brasileira, Brasília, v.38, n.6, p.729-735, 2003.

CLEVELAND, C.J. The direct and indirect use of fossil fuels and electricity in USA agriculture, 1910-1990. Agriculture, Ecosystems and Environment, Amsterdam, v.55, n.2, p.111-21, 1995.

COMITRE, V.A. questão energética e o padrão tecnológico da agricultura brasileira. Informações Econômicas, São Paulo, v.25, n.12, p.29-35, 1995.

DOERING III, O.C.; CONSIDINE, T.J.; HARLING, C.E. Accouting for tillage equipment and other machinery in agricultural energy analysis. West Lafayette: Purdue University, 1977. 4 p. (Agr. Exp.Sta. NSF/RA - 770128).

DRUMOND, L.C.D.; ZANINI, J.R.; AGUIAR, A.P.A.; RODRIGUES, G.P.; FERNANDES, A.L.T. Produção de matéria seca em pastagem de Tifton 85 irrigada, com diferentes doses de dejeto líquido de suíno. Engenharia Agrícola, Jaboticabal, v.26, n.2, p.426-433, 2006.

GOMES FILHO, R.R.; MATOS, A.T.; SILVA, D.D.; MARTINEA, H.E.P. Remoção da carga orgânica e produtividade de aveia forrageira em cultivo hidropônico com águas residuárias da suinocultura. Revista Brasileira de Engenharia Agrícola e Ambiental, Campina Grande, v.5, n.1, p.131-134, 2001.

KOSIOSKI, G.V.; CIOCCA, M.L.S. Energia e sustentabilidade em agroecossistemas. Ciência Rural, Santa Maria, v.30, n.4, p.737-745, 2000.

MACEDÔNIO, A.C.; PICCHIONI, S.A. Metodologia para o cálculo do consumo de energia fóssil no processo de produção agropecuária. Curitiba: Secretaria de Estado da Agricultura, 1985. v.1, $95 \mathrm{p}$.

MEDEIROS, L.T.; REZENDE, A.V.; VIEIRA, P.F.; CUNHA NETO, F.R.; VALERIANO, A.R.; CASALI, A.O.; GASTALDELLO JÚNIOR, A.L. Produção e qualidade da forragem de capim-marandu fertirrigada com dejetos líquidos de suínos. Revista Brasileira de Zootecnia, Viçosa, v.36, n.2, p.309-318, 2007.

OETTING, L.L. Avaliação de diferentes marcadores para a determinação da digestibilidade e taxa de passagem do alimento em suínos. 2002. 59 f. Dissertação (Mestrado em Energia Nuclear na Agricultura) - Centro de Energia Nuclear na Agricultura, Universidade de São Paulo, Piracicaba, 2002.

OLIVEIRA, P.A.V. Manual de manejo e utilização dos dejetos de suínos. Concórdia: EMBRAPA Centro Nacional Suínos e Aves, 1993. 188 p. (Documentos, 27). 
OLIVEIRA, W. Uso de água residuária da suinocultura em pastagens da Brachiária decumbens e grama estrela Cynodom plesctostachyum. 2006. 104 f. Dissertação (Mestrado em Irrigação e Drenagem) - Escola Superior de Agricultura "Luiz de Queiroz", Universidade de São Paulo, Piracicaba, 2006.

PELLIZZI, G. Use of energy and labour in Italian agriculture. Journal of Agricultural Engineering Research, Silsoe, v.52, n.2, p.111-119, 1992.

PEREIRA, B.D.; MAIA, J.C.S.; CAMILOT, R. Eficiência técnica na suinocultura: efeito dos gastos com o meio ambiente e da renúncia fiscal. Revista Brasileira de Engenharia Agrícola e Ambiental, Campina Grande, v.12, n.2, p.200-204, 2008.

PIMENTEL, D. Handbook of energy utilization in agriculture. Boca Raton: CRC Press, 1980. $475 \mathrm{p}$.

PRACUCHO, T.T.G.M.; ESPERANCINE, M.S.T.; BUENO, O.C. Análise energética e econômica da produção de milho (Zea mays) em sistema de plantio direto em propriedades familiares no município de Pratânia - SP. Energia na Agricultura, Botucatu, v.22, n.2, p.94-109, 2007.

QUESADA, G.M.; BEBER, J.A.C.; SOUZA, S.P. Balanços energéticos: uma proposta metodológica para o Rio Grande do Sul. Ciência e Cultura, São Paulo, v.39, n.1, p.20-28, 1987.

QUESADA, G.M.; PEREIRA FILHO, O.P.; BEBER, J.A.C.; NEUMANN, P.S. Energia, organização social e tecnologia. Ciência e Ambiente, Santa Maria, v.2, n.2, p.13-29, 1991.

RODRIGUES, K.F.; RODRIGUES, P.B.; FREITAS, R.T.F.; FIALHO, E.T.; BERTECHINE, A.G.; NAGATA, A.K. Desempenho e rendimento de carcaça de frangos de corte no período de 22 a 42 dias de idade alimentados com dietas contendo diferentes relações lisina digestível: proteína bruta. Revista Brasileira de Zootecnia, Viçosa, v.37, n.4, p.645-652, 2008.

ROMERO, M.G.C.; BUENO, O.C.; ESPERANCINI, M.S.T. Eficiência energética e econômica em sistemas familiares de produção de algodão. Informações Econômicas, São Paulo, v.38, n.1, p.7-19, 2008.

SANTOS, T.M.B.; LUCAS JÚNIOR, J. Balanço energético em galpão de frangos de corte. Engenharia Agrícola, Jaboticabal, v.24, n.1, p.25-36, 2004.

SERRA G.; HEEZEN, A.M.; MOREIRA, J.R.; GOLDEMBERG, J. Avaliação da energia investida na fase agrícola de algumas culturas. Brasília: Secretaria de Tecnologia Industrial, 1979. 86 p.

SIQUEIRA, R.; GAMERO, C.A.; BOLLER, W. Balanço de energia na implantação e manejo de plantas de cobertura de solo. Engenharia Agrícola, Jaboticabal, v.19, n.1, p.80-89, 1999.

SPEARLING, M. Von. Lagoas de estabilização. Belo Horizonte: Editora da UFMG, 1996. 134 p.

TEIXEIRA, C.A.; LACERDA FILHO, A.F.; PEREIRA, S.; SOUZA, L.H.; RUSSO, J.R. Balanço energético de uma cultura de tomate. Revista Brasileira de Engenharia Agrícola e Ambiental, Campina Grande, v.9, n.3, p.429-432, 2005.

TURCO, J.E.P.; FERREIRA, L.F.S.A.; FURLAN, R.L. Consumo e custo de energia elétrica em equipamentos utilizados em galpão de frangos de corte. Revista Brasileira de Engenharia Agrícola e Ambiental, Campina Grande, v.6, n.3, p.519-522, 2002.

ZANINI, A.; CAMPOS, A.T.; PRESTES, T.M.V.; DALMOLIN, M.F.S.; CAMPOS, A.T.; KLOSOWSKI, E.S. Análise do consumo de energia na produção de silagem de milho em plantio direto. Acta Scientiarum Animal Science, Maringá, v.25, n.2, p.249-253, 2003. 